\title{
Editorial
}

\section{Cytosolar protein delivery for therapeutic purpose}

\author{
Moumita Ray* \\ Department of Chemistry, University of Massachusetts Amherst, 710 North Pleasant Street, Amherst, MA 01003, USA
}

Proteins are an integral part of every organism [1]. It plays a crucial role in performing essential functions in growth, development and metabolic regulation [2]. Many diseases arise due to any abnormality in the functioning of proteins. Therefore, protein therapeutics has a tremendous opportunity in alleviating diseases. Thus, far, protein therapeutics has increased in number and their frequency of use since insulin being used as a therapeutic. Currently, more than 100 proteins or peptides have been approved as drug by FDA. However, protein therapeutics is still in infancy.

The key aspect of using protein for therapy is to deliver proteins into cells [3]. However, there are two major challenges for intracellular protein delivery: 1. Delivering unmodified functional protein into cells; 2 . Rapid cytosolic release of the protein after delivery. Mechanical delivery methods such as electroporation or microinjection have been widely used to deliver protein into cells [3]. However, these methods require specialized equipment and are disruptive in nature, limiting their use in vivo. Another popular approach is covalent modification of proteins using cell penetrating peptides (CPP) [4]. Here, CPP linked proteins are uptaken by cells via endocytic mechanism, resulting in slow or no release of proteins in cytosol.

Supramolecular carriers-based delivery methods, on the other hand, operate via non-covalent association with proteins. This allows transport of unmodified proteins into cells, retaining its structure and function. To date, various supramolecular carriers such as polymers, liposomes, nanoparticles stabilized nanocapsules (NPSCs) have been developed to facilitate protein delivery into cells. Among these, NPSCs are significant. In the recent studies, NPSCs have been shown to deliver GFP directly and rapidly into the cytosol [5]. The delivered protein was distributed throughout the cell uniformly. No sign of endosomal entrapment was observed. Further, NPSCs were used to achieve intracellular targeting to peroxisomes and nucleus [6]. Additionally, therapeutic protein caspase-3 (CASP3) was efficiently delivered into cells using NPSCs, resulting in induction of apoptosis. Therefore, NPSCs proved to be effective vehicle for intracellular delivery and hence for protein therapy.

\section{References}

1. Leader B, Baca QJ, Golan DE (2008) Protein therapeutics: a summary and pharmacological classification. Nat Rev Drug Discov 7: 21-39. [Crossref]

2. Walsh G (2010) Biopharmaceutical benchmarks. Nat Biotech 28: 917-924. [Crossref]

3. Fu A, Tang R, Hardie J, Farkas ME, Rotello VM (2014) Promises and Pitfalls of Intracellular Delivery of Proteins. Bioconjugate Chem 25: 1602-1608. [Crossref]

4. Brock R (2014) The Uptake of Arginine-Rich Cell-Penetrating Peptides: Putting the Puzzle Together. Bioconjugate Chem 25: 863-868.

5. Tang R, Kim CS, Solfiell DJ, Rana S, Mout R, et al. (2013) Direct Delivery of Functional Proteins and Enzymes to the Cytosol Using Nanoparticle-Stabilized Nanocapsules. ACS Nano 7: 6667-6673. [Crossref]

6. Ray M, Tang R, Jiang Z, Rotello VM (2015) Quantitative Tracking of Protein Trafficking to the Nucleus Using Cytosolic Protein Delivery by Nanoparticle-Stabilized Nanocapsules. Bioconjugate Chem 26: 1004-1007.
Copyright: (C2016 Ray M. This is an open-access article distributed under the terms of the Creative Commons Attribution License, which permits unrestricted use, distribution, and reproduction in any medium, provided the original author and source are credited.
Correspondence to: Moumita Ray, Department of Chemistry, University of Massachusetts Amherst, 710 North Pleasant Street, Amherst, MA 01003, USA, E-mail:moumita@chem.umass.edu

Received: October 01, 2016; Accepted: October 21, 2016; Published: October 25,2016 